\title{
An investigation of list types and cues to facilitate initial reading vocabulary acquisition'
}

\author{
RUTH NORENE HARTLEY, INSTITUTE FOR MATH- \\ EMATICAL STUDIES IN THE SOCIAL SCIENCES, STANFORD \\ UNIVERSITY, Stanford, Califormia 94305
}

Six instructional methods for initial reading vocabulary acquisition that were concerned with two list types combined with three sources of cue, using 127 first-graders divided into six treatment groups, were investigated. The Ss in each treatment received four types of tests to determine the level of performance for each treatment. Three sources of variation were significant: (a) ability grouping, (2) the interaction of list type and cue, and (3) the interaction of list type, sex, and ability grouping.

This study was designed to investigate two list types (minimal and maximal contrast) combined with three sources of cue (the word itself, a picture cue, and a context cue) in relation to their merit for initial reading vocabulary acquisition.

Fries (1963) has advocated the use of minimal contrast lists to teach the regularities found in the language. Rotberg \& Woolman (1963) found that learning was more effective when groups of stimuli were composed of similar items. Rothkopf (1958) found that lists which have dissimilar items (maximal contrast) were learned more rapidly than lists with small or minimal differences. Heilman (1961) has stated that pictures are of considerable help in arriving at unknown words. In contrast, Samuels (1967) found that pictures may miscue or divert attention from the printed word. Tinker \& McCullough (1962) have asserted that instruction on words in context is valuable but that teaching words in isolation is ineffective. Bloomfield \& Barnhart (1961) have claimed that context only places an added burden on the child when he should be concentrating on the visual stimuli of the printed word.

Materials

The stimulus material consisted of four minimal contrast lists and four maximal contrast lists. The words from each minimal contrast list were randomly assigned to one of the maximal contrast lists. A simple colored picture of the object identified with the word was used for the pictorial material. The context material was a simple sentence referring to the same object used in the pictorial material.

Procedure

There were 127 first-grade children from two schools in the sample. A stratified random assignment procedure was used based on sex, school, ability grouping, and class membership to assign Ss to each of the six treatment groups.

Each $S$ in each treatment group received four types of tests: (1) the 10 learning test trials, (2) the 24-h tests, (3) a posttest, and (4) a transfer test. The following is a sample of the sequence of events for the experiment:

Day 1. Study and test trials for List 1.

Day 2. Twenty-four $h$ test on List 1.

Study and test trials for List 2 .

Day 3. Twenty-four h test for List 2.

Study and test trials for List 3.

Day 4. Twenty-four h test for List 3. Study and test trials for List 4.

Day 5. Twenty-four h test on List 4. Transfer test.

Day 10. Posttest

A study trial consisted of an introductory statement about the likenesses and differences of the words in the list. Each word in the list was then presented with the proper stimulus for the treatment.

The procedure for each type of test was the same. A word was presented to the $S$. The $S$ was asked to say the word. There was no feedback on the tests.

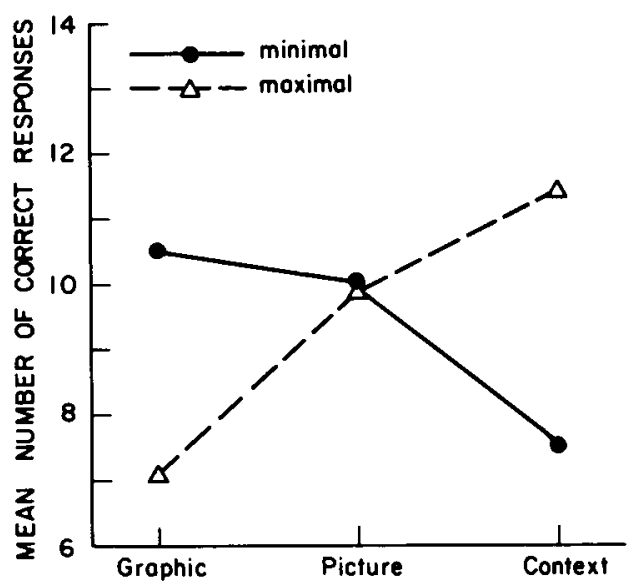

Fig. 1. Posttest: Mean number of correct responses on each list type and cue.

\section{Results}

The data were analyzed using an analysis of variance. There were three levels of cue, and two levels each of list type, sex, and ability grouping. The data for each test were analyzed separately.

The main effect of high and low ability grouping was significant on all tests. As would be expected the high ability group made more correct answers than the low ability group. The results indicated that the differences in performance were related to the level of performance, in general, rather than significantly different patterns of performance on each list type and cue combination.

The two-way interaction of list type and cue was significant on each test. The same general pattern of performance existed on all tests for this interaction. The Ss who received only the graphic stimulus with minimal contrast lists made more correct answers than those who received this cue with maximal contrast lists. The Ss who received the graphic stimulus plus a context cue with maximal contrast lists made more correct answers than those who received the same cue with minimal contrast lists. The Ss who received the graphic stimulus plus a picture cue made nearly an equal number of correct responses when this cue was presented with minimal and maximal contrast lists. Figure 1 shows the effect of the interaction in the posttest.

The three-way interaction of list type, ability grouping, and sex was significant. The boys in the high ability group made more correct answers on maximal contrast lists on all tests and the girls in the high ability group made more correct responses on minimal contrast lists on all tests. The low ability group did not present such a consistent pattern over all tests. On the learning test trials and the 24-h test, both boys and girls in the low ability group who received maximal contrast lists made more correct responses. On the posttest both boys and girls in the low ability group made more correct answers on minimal contrast lists. The transfer test results indicated that the boys in the low ability group who had minimal contrast lists made more correct answers and that the girls in the low ability group made nearly an equal number of correct answers on both minimal and maximal contrast lists.

Conclusions

The results on this experiment indicated that it is not possible to say that one list type and cue combination is better than another. Instead it is necessary to consider which combinations are to be used for an optimal learning situation. Furthermore, because of the differences found between the performance of boys and girls within ability groups, it would also seem to be advisable to consider these factors in planning an instructional program. 


\section{REFERENCES}

BLOOMFIELD, L., \& BARNHART, C. L. Let's read: a linguistic approach. Detroit: Wayne University Press, 1961.

FRIES, C. C. Linguistics and reading. New York: Holt, Rinehart, and Winston, 1962.

HARTLEY, R. N. An investigation of list types and cues to facilitate initial reading vocabulary acquisition. Unpublished doctoral dissertation, Stanford University, 1968.

HEILMAN, A. The principals and practices of teaching reading. Columbus: Charles E. Merrill Books, Inc., 1961.

ROTBERG, I. C., \& WOOLMAN, M. Verbal paired-associate learning as a function of grouping similar stimuli or responses. $J$, exp. Psychol, 1963, $65,47-51$.
ROTHKOPF, E. Z. Stimulus similarity and sequence of stimulus presentation in paired-associate learning. J. exp. PsychoL, 56, 114-122.

SAMUELS, S. J. Attentional process in reading: the effect of pictures on the acquisition of reading responses. J. educ. Psychol, 1967, 58, 337-352.

TINKER, M., \& McCULLOUGH, C. Teaching elementary reading (2nd ed.). New York: Appleton-Century-Crofts, Inc., 1962.

\section{NOTE}

1. The support for this research was provided by the U. S. Office of Education, Grants OE-5-10050, OEC-4-6-061493-2089, and the National Institute of Health, Grant MH-6154. The author extends thanks to Professor Richard C. Atkinson for his continued support and suggestions throughout the course of this study. 